\title{
HEREDITARY BREAST AND OVARIAN CANCER PATIENTS HAVE A FAMILY HISTORY OF CANCER OUTSIDE THE SPECTRUM OF THE SYNDROME, MIMICKING LYNCH AND LI-FRAUMENI SYNDROMES
}

Elisângela de Paula Silveira Lacerda¹, Rebeca Mota Goveia¹, Paula Francinete Faustino Silva', Thais Bonfim Teixeira², Ruffo de Freitas-Junior²

${ }^{1}$ Laboratório de Genética Molecular e Citogenética, Instituto de ciências Biológicas I, Universidade Federal de Goiás Goiânia (GO), Brazil.

${ }^{2}$ Centro Avançado de Diagnóstico da Mama, Hospital das Clínicas, Universidade Federal de Goiás - Goiânia (GO), Brazil.

Patients with pathogenic variants (PV) in the BRCA1 and BRCA2 genes have hereditary breast and ovarian cancer syndrome (HBOC). Some patients with HBOC have a family history $(\mathrm{FH})$ of different types of cancer not related to the syndrome. The objective of this study was to observe the FH profile of cancer in patients with HBOC syndrome. A total of 123 patients treated at the Advanced Breast Diagnostic Center (CORA) with clinical criteria suggestive of HBOC syndrome were selected according to the National Comprehensive Cancer Network (NCCN). The collection of $4 \mathrm{ml}$ of blood was performed, which was subjected to DNA extraction and PV analysis in the BRCA1 and BRCA2 genes by next generation sequencing. The data were analyzed using the Sophia DDM and Ion Reporter software. The variants were considered to be pathogenic according to the ACMG criteria. It was found that among 123 patients analyzed, 19 had HBOC syndrome, of whom 5 were related. Thus, we had 16 families with HBOC syndrome. Among the 16 families, 14 (87.5\%) had FH from cancers related to HBOC syndrome, 9 (56.25\%) had FH from cancers not related to HBOC syndrome, and $1(16.25 \%)$ did not have FH cancer. A total of $8(50 \%)$ of families with HBOC also met the NCCN criteria for other hereditary cancer syndromes, 3 (18.75\%) for Li-Fraumeni syndrome (LFS) and HBOC, 3 (18.75\%) for Lynch syndrome (LS) and HBOC, and 2 (12.5\%) for HBOC, LFS, and LS. The most common cancers observed outside the common spectrum of HBOC syndrome in families were stomach cancer (25\%), intestine (18.75\%), liver (18.75\%), and skin (18.75\%). These data suggest the importance of a complete assessment of FH in patients with HBOC syndrome to better understand its relationship with the predisposition to different types of cancer.

Keywords: HBOC; Hereditary Breast Cancer; Li-Fraumeni Syndrome; Lynch Syndrome; NGS. 